\title{
O Processo de Ensino e Aprendizagem em Educação em Saúde no Município Brasileiro de Lages
}

\author{
The Process of Teaching and Learning in Health Education in the \\ Brazilian City of Lages
}

http://dx.doi.org/10.5007/2178-4582.2013v47n2p254

\author{
Anderson Chagas de Oliveira, Bruna Pereira Dondé, Ana Paula Veloso, \\ Priscila Godinho da Silva e Rodrigo Diaz de Vivar Y Soler \\ Universidade do Planalto Catarinense, Lages/SC, Brasil
}

\begin{abstract}
O processo ensino-aprendizagem ocorre em variados contextos: nas escolas, universidades, cursos técnicos, na área da saúde e dentre muitas outras áreas. Quando pensamos a questão da educação em saúde, no Brasil - principalmente nas Unidades Básicas de Saúde (UBS), é preciso indagar como ocorre a relação entre a comunidade e os profissionais. O método Paulo Freire é mais do que um instrumento pedagógico, caracterizandose também como uma ferramenta de emancipação cultural e social. Dessa maneira, a pesquisa que deu origem a este artigo teve como objetivo compreender como acontece o processo de ensino e aprendizagem em Educação em Saúde em uma Unidade Básica de Saúde do município de Lages, estado de Santa Catarina, tomando como referência o método de Paulo Freire. A coleta de dados foi feita a partir de um questionário semiestruturado respondido por duas profissionais da saúde do local. Os resultados indicam a existência de vários obstáculos para que ocorra um efetivo processo de ensino e aprendizagem nas Unidades Básicas de Saúde.
\end{abstract}

Palavras-chave: educação em saúde $\square$ ensino e aprendizagem - Método Paulo Freire
The teaching-learning process occurs in a variety of contexts: in schools, universities, technical courses, in health and among many other areas. When we think the issue of health education in Brazil - especially at the Basic Health Units (UBS-Portuguese initials), one must ask about the relationship between the community and the professionals. The Paulo Freire method is more than a teaching tool; it can be also characterized as a tool for cultural and social emancipation. Thus, the research that gave rise to this paper aimed to understand the process of teaching and learning in Health Education in a Basic Health Unit in the city of Lages, Santa Catarina, taking Paulo Freires method as reference. Data collection was made from a semi-structured questionnaire answered by two local health professionals. The findings indicate the existence of several barriers for the occurrence of an effective teaching-learning process within the Basic Health Units.

Keywords: health education - teaching and learning - Paulo Freires Method

\section{Introdução}

As questões que envolvem o ensino e a aprendizagem ocorrem nas mais variadas situações da realidade brasileira e do mundo. Em nosso país, encontramos processos de ensino e de aprendizagem nas escolas, universidades, cursos técnicos e/ou profissionalizantes, na área da saúde, meio ambiente, artes plásticas, dentre muitas outras áreas.

A educação na área da saúde pode ser vista como um campo de práticas que ocorre nas relações sociais estabelecidas pelos profissionais de saúde entre si, com a instituição e, sobretudo, 
com o usuário, no desenvolvimento cotidiano de suas atividades (L'ABATTE, 1994 apud PINAFO et al, 2011, p. 202).

Diversas publicações do Ministério da Saúde (BRASIL, 1997) apontam o Programa de Saúde da Família (PSF) como a estratégia política que tem a intenção de oferecer uma atuação focada nos princípios da vigilância em saúde. Quando se pensa a questão da educação em saúde, realizada principalmente nas Unidades Básicas de Saúde, deve-se questionar como ocorre essa relação entre a comunidade e os profissionais de saúde. Além disso, torna-se importante compreender como os profissionais entendem o processo de ensino e aprendizagem em educação em saúde no seu contexto de trabalho.

Existem dois tipos de método para se fazer educação em saúde: o tradicional, em que os profissionais da saúde são os detentores do saber e a relação com a comunidade ocorre verticalmente, isto é, de cima (profissionais) para baixo (população); e o da educação popular em saúde, iniciada a partir da metodologia dialógica de Paulo Freire, em que a comunidade é vista como detentora de conhecimentos acerca de sua saúde, de suas vivências. Nesta perspectiva, a relação é horizontal, ou seja, os profissionais da área da saúde são os mediadores entre seus conhecimentos e aqueles oriundos da realidade de cada comunidade.

O Sistema Único de Saúde é uma formulação política e organizacional para o redirecionamento dos serviços e ações da saúde. É assim definido por seguir a mesma doutrina e os mesmos princípios organizativos em todo o território nacional, sob a responsabilidade das três esferas do governo: a federal, a estadual e a municipal. Não se trata de um serviço ou de uma instituição, mas um sistema, que significa um conjunto ou uma unidade de serviços e ações com vistas a um fim comum. Esses elementos integrantes do sistema referem-se, ao mesmo tempo, às atividades de promoção, proteção e recuperação da saúde.

O método Paulo Freire é mais do que um instrumento pedagógico, caracterizando-se também como uma ferramenta de emancipação cultural e social. Para a Psicologia, Freire também contribuiu de forma efetiva para o entendimento de uma práxis que concebe a aprendizagem como modificadora dos modos de pensar, dos fazeres das pessoas, de sua visão de mundo, assim como da sua qualidade de vida. Esses pontos são importantes dentro da Psicologia, ciência esta que visa - assim como o método freireano - uma mudança do ambiente social dos indivíduos para que possam adquirir mais autonomia, independência e capacidade crítica a respeito dos problemas cotidianos, políticos e sociais.

Esse método é tão conhecido pelo fato de desconstruir o formato por meio do qual o processo de aprendizagem costumava ser feito. Freire direcionou seus estudos para atividades com trabalhadores e homens do campo, implementando seu método de forma a que as pessoas não só aprendessem a ler, mas aprendessem a compreender o que acontecia ao seu redor, trazendo a realidade social para o processo de ensino-aprendizagem. O que Freire quis dizer 
com realidade das pessoas, se traduz no cotidiano do homem do campo, do trabalhador da cidade. Nada mais é do que cenas e fatos que fazem parte do seu dia a dia.

Os fatos cotidianos facilitam o processo e fazem com que surjam, a partir daí, um verdadeiro conhecimento, não apenas a alfabetização, pois a partir do momento em que os sujeitos se tornam capazes de Ter uma palavra e de terem uma opinião crítica a respeito dela, então o conhecimento acontece. Em Psicologia, algumas abordagens trabalham na mesma perspectiva de Freire, quando dizem, por exemplo, que devemos intervir de acordo com as necessidades do lugar, das pessoas, e não com formatos prontos que encaixam os indivíduos em situações que não correspondem às suas características, ao seu ambiente, à sua situação atual, e todo um leque de aspectos que envolvem a vida dos sujeitos.

No trabalho do PSF (Programa de Saúde da Família) o método Paulo Freire tem sido bastante pesquisado, existindo diversos estudos que apontam a sua eficácia nesse tipo de ambiente. A população que procura uma UBS tem, em geral, uma ideia vaga deste serviço, enxergando-o apenas como um lugar onde é possível conseguir tão somente remédios, atestados, requisições e consultas. Essa é uma grande queixa dos profissionais de saúde que trabalham de forma interdisciplinar na tentativa de conscientizar as pessoas a respeito da própria saúde. Os profissionais relatam que deveria haver uma transformação no conceito do que é esse serviço, o que deveria acontecer por meio de um projeto de educação em saúde.

Um trabalho que utilize o método freireano tem início com um importante levantamento de identificação das necessidades primárias das pessoas atendidas, para que sejam trabalhadas e para que, posteriormente, o processo de conscientização aconteça. Afinal, saltos qualitativos não existem; a mudança de comportamento e a aprendizagem são um processo, mas podem ser menos dolorosos se levarem em consideração as necessidades da população com a qual se trabalha, fazendo-a aprender com a própria realidade. Para Fernandes e Backes (2010, p. 568), a articulação entre educação e saúde sob o ponto de vista da relação interpessoal, cuidado e respeito, se constitui como uma das mais ricas fontes de interdisciplinaridade $\square$.

$\mathrm{Na}$ pesquisa que dá origem a este artigo, tratou-se da questão dos processos de ensino e de aprendizagem da Educação em Saúde, que ocorrem nas Unidades Básicas de Saúde (UBS) de todo o país. A relevância social desta pesquisa relaciona-se à necessidade de compreender como se dá esse processo de ensino-aprendizagem em Educação em Saúde numa UBS do município de Lages, no Estado de Santa Catarina, de maneira a compreender os benefícios que tais práticas trazem para a população, bem como as dificuldades encontradas no intercâmbio entre os profissionais da saúde e a população. Do ponto de vista da relevância científica, a pesquisa procurou contribuir para que a Educação em Saúde fosse realizada de maneira ainda mais eficiente, procurando identificar as potencialidades e os entraves existentes nessa estratégia. De acordo com Fernandes e Backes: 
Uma das principais características da atenção primária do sistema Único de Saúde (SUS) é a criação de equipes multiprofissionais que devem agir a fim de desenvolver práticas de saúde com integralidade para atender populações delimitadas por áreas geográficas. A política de trabalho preconiza a visão do ser humano de forma contextualizada às suas condições demográficas, epidemiológicas, socioeconômicas, políticas e culturais para que as ações de saúde sejam cada vez mais direcionadas e eficazes (FERNANDES; BACKES, 2010, p. 568).

Esse processo de Educação em Saúde que ocorre nas Unidades Básicas de Saúde também está sujeito a inúmeras vicissitudes para sua implementação e correto funcionamento. Rodrigues e Ribeiro (2012) afirmam que para os profissionais, a ausência de materiais educativos e didáticos, a inexistência e/ou precariedade de locais para a realização das palestras, a resistência e o baixo nível socioeconômico e de escolaridade dos usuários podem ser frustrantes, levando à desmotivação para a realização de ações de Educação em Saúde.

\section{Histórico da Educação em Saúde}

Silva et al (2007) apresentam um histórico da educação em saúde no Brasil. Na segunda metade do século XIX, organizou-se uma ideia de pedagogia higiênica, sendo que as famílias da elite eram a população-alvo dessa prática. Iniciou-se, com isso, uma tentativa de europeização e urbanização dos hábitos dessa elite. No final do século XIX e início do século XX houve a estruturação das primeiras intervenções sistemáticas de educação em saúde, ampliadas às classes populares com o intuito de combater as epidemias de febre amarela, varíola e peste. O Estado identificava a ignorância e a falta de informação da população como causas para a existência das doenças e os males da saúde que, então, assolavam as cidades eram vistos unicamente como de responsabilidade da população. Entretanto, a educação relacionada à saúde tinha papel marginal.

A partir da década de 1920, com o fortalecimento econômico do complexo cafeeiro e do processo de industrialização, surgiu uma nova concepção de serviços de saúde, chamada saúde pública. Junto com essa concepção, aparece uma nova prática de educação voltada para a saúde, denominada educação sanitária $\square$ que surgiu com o papel de substituir os métodos repressivos das campanhas sanitárias pela persuasão e conscientização, ou seja, por métodos educativos e preventivos junto aos indivíduos e às coletividades. Esse modelo era baseado na visão de que as doenças não são apenas produzidas pelo meio externo, mas também pela consciência sanitária das pessoas.

Em meados da década de 1930, a ação estatal na área da saúde concentrase na construção de um sistema previdenciário, destinado às categorias de trabalhadores politicamente mais organizadas, e ações de caráter coletivo foram esvaziadas em favor da assistência médica individual. As ações educativas 
em saúde restringiram-se, assim, a programas e serviços destinados às populações marginalizadas, priorizando o combate às doenças infecciosas e parasitárias. Na década de 1940, estrutura-se o Serviço Especial de Saúde Pública (SESP), o qual se tornou um marco para o desenvolvimento das instituições de saúde no Brasil, principalmente devido às suas propostas no campo das programações de saúde. A Fundação SESP influenciou de forma importante a introdução da ideologia do desenvolvimento e participação comunitária e de educação de grupos.

Durante as décadas de 1950 e 1960, atribuiu-se um novo papel à educação em saúde. Surgiu a proposta de participação popular, na tentativa de canalizar e mobilizar a população para atuar em áreas sociais restritas. Entre os anos 1950 e 1960, a pedagogia da saúde pautou-se por uma ideologia modernizadora, objetivando remover obstáculos culturais e psicossociais às inovações tecnológicas de controle às doenças, a fim de manter o domínio estrutural da sociedade. Com o golpe militar de 1964, houve total esvaziamento da participação social nos rumos da previdência e a política de saúde voltou-se para a expansão de serviços médicos privados, especialmente hospitais, nos quais não havia espaço para ações de educação. Até à década de 1970, a educação em saúde foi basicamente uma iniciativa das elites políticas e econômicas, voltando-se para a imposição de normas e comportamentos considerados adequados por essas elites.

Esse movimento ficou conhecido como Movimento da Reforma Sanitária, ampliado com a incorporação de lideranças políticas sindicais populares e também parlamentares interessados na causa da saúde. Nas universidades, alguns estudos denunciavam os efeitos do modelo econômico sobre a saúde da população e a irracionalidade do sistema de saúde então existente. Iniciou-se profunda reflexão e grupos debatiam princípios e estratégias para se criar um sistema de saúde que atendesse as reais necessidades da população brasileira. Os princípios da Conferência de Alma-Ata (1978) em relação aos cuidados primários de saúde foram introduzidos no país. Ainda nessa época, o método educacional sistematizado por Paulo Freire tornou-se um eixo de referência para a relação entre profissionais de saúde e as classes populares. Abriu-se espaço para novas experiências no campo da educação em saúde, baseadas na dialogia de Paulo Freire, configurando enfim a educação popular em saúde.

A década de 1980 foi marcada por uma profunda crise de caráter político, econômico e social, repercutindo fortemente na condição de saúde da população, agravando as condições de vida, aumentando o desemprego, a desnutrição e a mobilidade dos grupos sociais menos favorecidos. Em 1986, ocorreu a VIII Conferência Nacional de Saúde, em Brasília, que destacou o conceito ampliado de saúde, colocado como dever do Estado. Boa parte de suas propostas foram incluídas pela Assembleia Constituinte, moldando posteriormente as diretrizes do Sistema Único de Saúde (SUS).

O Congresso Nacional aprovou, em 1990, a Lei orgânica da Saúde, sen-

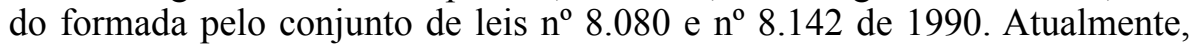
convivem no país dois modelos de Educação em Saúde, o modelo tradicional 
hegemônico, influenciado pelo positivismo e que centraliza o poder nos profissionais de saúde, considerados detentores do saber necessário para se ter uma vida saudável. Este modelo não busca a autonomia das pessoas, mas ao contrário, enfraquece a população, pois prescreve a educação em saúde de forma vertical. Já a educação popular em saúde se contrapõe ao autoritarismo da cultura sanitária e ao modo tradicional de definir, técnica e politicamente, as intervenções na área da saúde. Essa abordagem procura a transformação das relações de subordinação e de interlocução, favorecendo a autonomia e a participação da população comum, em interlocução entre saberes e práticas. Seu método parte do pressuposto de que as classes populares, possuem uma dinâmica própria sobre as doenças e seus processos de cura, adquirida no cotidiano, e que este saber deve ser respeitado e incorporado às práticas de saúde. Ocorre, assim, uma relação horizontal entre os profissionais da saúde - considerados mediadores - e a comunidade, por meio de um diálogo não-condutivista, acompanhado de um movimento para o fortalecimento comunitário que busca criar relações sociais mais justas.

\title{
Contextualização da Educação em Saúde
}

\begin{abstract}
A educação em saúde é entendida como um processo educativo de construção de conhecimentos em saúde que visa à apropriação temática pela população, tornando-se um conjunto de práticas do setor que contribui para aumentar a autonomia das pessoas no seu cuidado. Por fim, busca alcançar uma atenção de acordo com suas necessidades, como também potencializar o exercício do controle social sobre as políticas e os serviços de saúde para que estes respondam às necessidades da população (BRASIL, 2008).
\end{abstract}

Para Pinafo et al (2011) a Educação em Saúde é um recurso através do qual o conhecimento produzido pela ciência na área da saúde, intermediado pelos profissionais, objetiva atingir a vida cotidiana das pessoas, uma vez que a compreensão dos condicionantes da relação saúde-doença oferece subsídios para que novos hábitos e condutas de saúde possam ser adotados.

\footnotetext{
As intervenções de promoção da saúde propõem abordagens de fora do setor saúde, ou seja, abordagens que fortaleçam a busca de modificações das condições de vida, para que sejam dignas e adequadas; apontam para a transformação dos processos individuais de tomada de decisão para que levem à qualidade de vida e à saúde, e orientam-se ao conjunto de ações e decisões coletivas que possam favorecer a saúde e o bem-estar da população (PINAFO et al, 2011, p. 215).
}

Antes de a educação em saúde tornar-se a essência da Estratégia Saúde da Família (ESF), até o início do século XX, as preocupações focavam-se 
quase que exclusivamente nas situações de epidemia e, na área educacional, limitavam-se ao ensino de hábitos de higiene e mudança de comportamento, não considerando qualquer influência dos fenômenos sociais e, muito menos, as origens estruturais, econômicas e sociais dos problemas de saúde (ROECKER; MARCON, 2011).

Para Fernandes e Backes (2010), a introdução da Educação em Saúde e as práticas da Estratégia de Saúde da Família mostram-se atuais e necessárias, principalmente se acontecer a partir de uma visão horizontal, de troca de conhecimento e se não se organizar apenas como um processo ensino-aprendizagem, mas como ato de criação e transformação. O educador em saúde deve levantar problemas e soluções por meio de investigações e diálogos com os usuários da UBS. Assim, a realidade da comunidade pode ser contextualizada, sendo possível também uma identificação com os usuários do sistema, pois suas necessidades passarão a ser conhecidas. Dentro de um processo educativo, esses são passos importantes para se vencer os desafios que surgem.

\title{
Método Paulo Freire
}

A respeito do método pedagógico criado e desenvolvido por Paulo Freire, Brandão explica que:

\begin{abstract}
O material 'pra começo de conversa' do Método Paulo Freire está criado [...] quando: $1^{\circ}$ ) em uma comunidade comprometida com um trabalho de educação popular existem formados ou em formação, com o seu grupo de educandos e o seu animador [...] $2^{\circ}$ ) foi feito um primeiro momento do trabalho de pesquisa de descoberta do universo vocabular e/ou do universo temático. $3^{\circ}$ ) todo o material de pesquisa feita dentro e fora da comunidade foi reunido, organizado, discutido, inclusive com a gente do lugar. $4^{\circ}$ ) o instrumental do trabalho de alfabetização foi codificado, transformado em símbolos de uso no círculo de cultura: palavras geradoras, cartazes e fichas com as palavras, desenhos e fonemas, fotos, anotações com dados, etc. $5^{\circ}$ ) a equipe de trabalho e, sobretudo, os animadores de círculos de cultura, estão não só familiarizados com o método e o seu material específico para trabalho no lugar, com a sua gente, mas também treinados sobre o método a ponto de sabê-lo usar, ao mesmo tempo, com eficiência autônoma e criatividade (BRANDÃO, 2006, p. 40).
\end{abstract}

Para Fernandes e Backes (2010), a concepção dialógica de Freire tem a capacidade de ampliar as fronteiras de atuação da Saúde da Família, fornecendo maior resolutividade para as ações e melhor impacto nos indicadores de saúde e de qualidade de vida da população assistida. Considera-se esta uma dimensão de essencial importância na produção de cuidados de saúde, no processo de construção do SUS. 
É tão importante saber como os lavradores do lugar fazem o seu trabalho com a terra, como saber de que modo as mulheres guardam a sabedoria do cuidado de seus filhos. O vivido e o pensado que existem vivos na fala de todos, todo ele é importante: palavras, frases, ditos, provérbios, modos peculiares de dizer, de versejar ou de cantar o mundo e traduzir a vida (BRANDÃO, 2006, p. 26).

Ainda de acordo com Fernandes e Backes (2010), saúde e educação não podem ser dissociadas, pois caminham juntas, articulando-se como práticas sociais. Neste sentido, o método Paulo Freire pode vir a contribuir de forma efetiva para um redirecionamento do olhar dessas pessoas, que pensam no serviço oferecido apenas focando os ganhos secundários que podem ser obtidos, e não como uma forma de orientação, esclarecimento e ajuda para a prevenção de problemas de saúde, psicológicos e sociais, daquela comunidade.

Se torna responsabilidade dos profissionais da saúde atentar e praticar a educação em saúde como processo educativo de construção de conhecimentos em saúde que visa à apropriação sobre o tema pela população em geral (FERNANDES; BACKES, 2010, p. 568).

\section{Metodologia e análise dos resultados}

$\mathrm{O}$ trabalho de pesquisa foi realizado com o intuito de iniciar-se a compreensão de como ocorre o processo de ensino e aprendizagem em Educação em Saúde no município de Lages, Estado de Santa Catarina, a partir da compreensão de uma enfermeira (Profissional A) e de uma médica (Profissional B) que trabalham em uma UBS do município e participam dessas atividades. A escolha dessas profissionais levou em conta os seguintes fatores: (1) a pesquisa fez parte de um trabalho de uma disciplina de graduação em Psicologia, sendo o tempo para a sua realização de aproximadamente três meses; daí a escolha de apenas duas profissionais; (2) as profissionais que participaram da pesquisa são as responsáveis pela coordenação das atividades de Educação em Saúde na UBS pesquisada; (3) a UBS em questão divide-se em duas equipes, que atendem áreas distintas, com diferentes perfis populacionais (grau de instrução, renda familiar, número de habitantes por residência, entre outros), sendo que as profissionais pesquisadas atendem, cada uma, a uma dessas áreas, o que proporcionaria maior riqueza de informações para este trabalho. A pesquisa seguiu uma abordagem qualitativa. Segundo Pinto,

[...] a metodologia qualitativa de pesquisa em psicologia clínica considera a ciência como uma construção da subjetividade humana, em uma forma particular e dentro de um determinado sistema teórico. Considera também que essa forma de fazer 
ciência apresenta uma epistemologia específica, na qual a investigação é construída dentro do fenômeno estudado. É neste sentido que os princípios teóricos dessa metodologia de pesquisa legitimam o conhecimento por construção (PINTO, 2004, p. 74).

A coleta dos dados se deu por meio de um questionário semiestruturado, composto de 14 perguntas abertas e fechadas que abordaram temas de interesse desta pesquisa, de modo obtermos uma melhor compreensão e um maior aprofundamento acerca do objeto de interesse dos pesquisadores. A utilização de um questionário semiestruturado como instrumento de coleta de dados foi considerada como a melhor opção, dado o fato de que as profissionais selecionadas alegaram falta de tempo para participarem de entrevistas. Segundo Richardson (1999), geralmente os questionários cumprem pelo menos duas funções: descrever as características e medir determinadas variáveis de uma comunidade. O questionário é um instrumento de coleta de dados formado por um conjunto ordenado de questões que, para serem respondidas, não necessitam, obrigatoriamente, da presença do pesquisador. Geralmente, esse questionário pode ser enviado ao entrevistado pelo correio ou por outra pessoa; sendo depois devolvido ao pesquisador, preenchido, da mesma maneira.

Os procedimentos de análise e interpretação dos dados foram baseados nas respostas que as participantes deram ao questionário proposto. Para Minayo et al (1994, p. 75-76), "a análise de conteúdos pode abranger as seguintes fases: pré-análise, exploração do material, tratamento dos resultados obtidos e interpretação". A exploração do material baseou-se também na leitura de livros e artigos científicos relacionados, utilizados como referencial teórico na análise e interpretação das respostas obtidas. Com esse fim, decidiu-se por fazer uso da análise do conteúdo, o que nos permitiu a formulação de cinco categorias, a saber: caracterização das participantes; a prática da Educação em Saúde na Unidade Básica de Saúde; dificuldades para se trabalhar com a Educação em Saúde; postura dos profissionais da área da saúde perante a Educação em Saúde e, por fim, processo de aprendizagem na Educação em Saúde e resultados alcançados.

\section{Caracterização dos participantes}

Como já foi dito, o questionário foi respondido por duas profissionais que atuam na UBS de um bairro do município de Lages-SC. A primeira respondente (profissional A) tem entre 25 e 30 anos e possui licenciatura plena em Enfermagem, especialização em Saúde da Família e estava, no momento da coleta de dados, concluindo uma especialização em Enfermagem em Ginecologia e Obstetrícia. A segunda profissional (profissional B) tem entre 31 e 35 anos, é graduada em Medicina, tendo feito residência em Medicina de Família e Comunidade. 


\section{A Prática da Educação em Saúde na Unidade Básica de Saúde (UBS)}

Nesta categoria, buscou-se investigar o que as participantes entendem pelo tema Educação em Saúde; como se dá o processo de ensino e aprendizagem nessa área; e se o profissional vê benefícios nesse processo. No que se refere ao entendimento do tema, ambas responderam que é uma forma de compartilhar e transmitir conhecimentos para a população; uma delas acrescentou que é possível utilizar a cultura local na prevenção de doenças. Segundo elas, é importante o profissional ter conhecimento da cultura local, para que a transmissão de informações sobre saúde para a comunidade seja útil e adaptada à realidade.

Quanto ao processo de ensino-aprendizagem na Educação em Saúde, as participantes concordam e ressaltam que tanto os profissionais, quanto usuários aprendem, ou seja, ocorre uma troca de saberes entre a comunidade e os profissionais da UBS. Este fato nos remete ao método de Paulo Freire, que propõe uma relação horizontal entre profissionais e comunidade, possibilitando a aprendizagem e, consequentemente, gerando autonomia, novas atitudes e a capacidade crítica e de mudança. Os depoimentos das profissionais pesquisadas são ilustrativos dessa percepção:

A partir da realidade local e ao conhecimento da população, através de discussões com a comunidade e da troca de saberes (Profissional B).

Através de dinâmicas, conversas com grupos de pacientes, teatrinhos (educações em saúde para crianças, por exemplo), projeção de slides/filmes curtos com datashow, etc. (Profissional A).

Uma das participantes menciona a utilização de outras técnicas que também servem como ferramentas educativas nesse processo de aprendizagem. Segundo ela, é importante o uso de meios tais como filmes e teatros, principalmente quando se trata de um público de crianças, pois essa forma de ensino possibilita melhor apreensão do conhecimento. Quando indagadas se veem benefícios nesse processo de Educação em Saúde, as respostas foram as seguintes:

Sim, pois é um meio de instrumentalizar a população para que esta possa buscar melhorar sua qualidade de vida e saúde (Profissional A).

Sim, através do conhecimento e percepção de hábitos nocivos à saúde é possível modificar ou adaptar situações que prejudicam a saúde (Profissional B). 
Ambas as profissionais afirmam a importância do processo de Educação em Saúde que, além de facilitar, acrescenta conhecimentos que promovem a saúde da população e dá resultados, como melhores cuidados com a própria saúde e melhor qualidade de vida.

\section{Dificuldades para se trabalhar com a Educação em Saúde}

Esta categoria objetivou identificar quais os fatores que mais dificultam o processo de funcionamento da Educação em Saúde em uma UBS. O levantamento dos pontos problemáticos favorece um potencial de ação, no sentido de eliminar e/ou minimizar os problemas relatados, bem como possibilita uma visão holística de possíveis intervenções nesta organização. Por meio da análise criteriosa dos dados, percebeu-se que as participantes acreditam que as principais dificuldades encontradas para a realização da Educação em Saúde são: a falta de participação da população e a ausência de locais e materiais adequados para estas atividades.

Dificuldades secundárias também foram citadas, tais como: equipe desmotivada, falta de entendimento da população sobre o que lhe é repassado, crença da população de que $\square$ governo $\square$ é o responsável pela sua saúde e profissionais que não valorizam a Educação em Saúde. Sobre isso, a literatura nos informa que:

[...] como justificativa para a prática ainda tímida, apareceram: a grande demanda de pacientes; a falta de envolvimento, compromisso e interesse dos profissionais para com a população; a falta de informação dos usuários; a falta de material de divulgação e de veículos para que as informações saiam da Unidade e se estendam à comunidade (FERNANDES; BACKS, 2010, p. 571).

Quando questionadas sobre qual dos fatores era considerado aquele que mais dificulta o processo de ensino-aprendizagem na Educação em Saúde, ambas concordaram que a população é a que mais oferece desafios. Esta informação vem ao encontro do que diz a literatura, pois Fernandes e Backs (2010) afirmam que a população concebe a Educação em Saúde somente como uma obrigação dos profissionais de informar e explicar as atitudes corretas em relação à saúde. Os mesmos autores afirmam ainda:

[...] Expressaram a dificuldade que grande parte da população apresenta para entender as informações que eles tentam passar, gerando um processo repetitivo e cansativo frente à ignorância $\square$ das pessoas. O medo, a vergonha, a timidez e a coação da população aparecem como barreiras ao processo educacional que vem sendo feito pela equipe (Ibid., p. 570). 
Uma das participantes assinalou também a questão da falta de local adequado para a realização das atividades. Porém, como apenas uma alternativa deveria ser assinalada nesta questão, consideramos aquela que coincidia com o próprio relato anterior da profissional. Temos aqui informações importantes, pois as duas profissionais elegeram a população como o fator que mais dificulta a Educação em Saúde. O método Paulo Freire afirma que todo e qualquer processo de ensino e aprendizagem deve levar em conta a realidade na qual aquela comunidade/pessoas estão inseridas, como ainda nos informam Fernandes e Back :

[...] No sentido que o educador Paulo Freire atuava: não no sentido de estabelecer esquemas fechados com resolubilidades formadas, mas sim de conhecer a realidade dos sujeitos e conjuntamente com eles visualizar possibilidades de transformações, criando ou ampliando horizontes de trabalho (FERNANDES; BACKS, 2010, p. 568).

A partir do que propõe o método Paulo Freire, pode-se levantar a hipótese de que estas atividades estejam sendo implementadas de forma que os conteúdos fiquem alienados ao verdadeiro contexto daquelas pessoas, e como não carregam nenhum significado para elas, talvez por isso não haja participação efetiva. Obviamente, devemos levar em consideração o fator cultural que, certamente, interfere no processo de participação das pessoas nas atividades de Educação em Saúde. Por fim, apesar das dificuldades apresentadas, as profissionais relatam que é possível, sim, algumas vezes, acontecer um processo de aprendizagem efetivo na Educação em Saúde, conforme nos indica o seguinte relato:

Sim. Quando há participação efetiva da população e o fato de ter vários atores envolvidos e comprometidos com sua saúde é possivel uma aprendizagem efetiva (Profissional A).

As profissionais pesquisadas apontaram também outro ponto importante, ao relatarem que, dependendo do grupo, realmente a possibilidade de a aprendizagem ocorrer de forma satisfatória é maior do que em outros grupos, como indica a seguinte fala:

[...] Às vezes, pois depende também do grupo abordado. Por exemplo, geralmente as gestantes têm melhor compreensão do que os idosos dos grupos de diabetes e hipertensão (Profissional B).

Essa informação vem ao encontro do que diz a literatura de Paulo Freire, quando este fala que se deve adaptar o conhecimento à realidade das pessoas. Assim, é possível supor que para os grupos que têm mais facilidade de traba- 
lhar a Educação em Saúde, esse conhecimento faça mais sentido do que para aqueles com quem se têm mais dificuldades. A solução deste problema seria readaptar as atividades para que não fossem apenas uma repetição de conceitos, em grupos diferenciados, mas que fossem conhecimentos direcionados para questões específicas e reais da vida daquelas pessoas.

\section{Postura dos profissionais da área da saúde perante a Educação em Saúde}

Nesta categoria foram levantadas informações acerca da postura que os profissionais de saúde adotam diante da Educação em Saúde. Em outras palavras, como veem o seu papel dentro deste processo e como se dá a atuação dos profissionais no processo de ensino-aprendizagem. As participantes trouxeram várias informações a respeito de como os profissionais da UBS trabalham. Deve-se ressaltar, primeiramente, que ambas concordam que a equipe profissional costuma estabelecer um diálogo com a comunidade, levantando as suas necessidades para as intervenções em Educação em Saúde. Também dizem que, apesar de a equipe estabelecer esse diálogo com a comunidade, existem algumas variáveis que prejudicam o processo. Em relação a essas variáveis, houve divergência entre as respostas das profissionais:

Sim. Porém a população é pouco participativa e não levanta problemas, partindo da equipe perceber os principais problemas (Profissional A).

Sim, nas reuniões de comunidade, porém, devido à falta de agentes de saúde e não autorização da Secretaria Municipal de Saúde, faz muito tempo que não ocorre (Profissional B).

Por meio destas falas, pode-se perceber que diferentes fatores interferem para a obstrução de um efetivo processo de diálogo entre os profissionais e os usuários dos serviços de saúde. Esse distanciamento faz com que o processo de não participação nas atividades propostas pela UBS fique cada vez mais claro. Segundo o método Paulo Freire, o educador (neste caso, o profissional de saúde) deve ser um agente participador da comunidade, alguém que conheça aquela realidade e que, de preferência, faça parte dela, saiba da sua história, para estar afetivamente mais próximo daquelas pessoas e, dessa forma, estabeleça esse diálogo tão necessário. Segundo Fernandes e Backs (2010), a prática da Educação em Saúde requer do profissional uma análise crítica da sua atuação, bem como uma reflexão do seu papel como educador.

Pelas respostas das participantes, foi possível perceber os sentimentos em relação ao seu papel como agentes fomentadoras e disseminadoras da Educação em Saúde dentro da UBS e para a comunidade. Obtivemos informações interessantes e, ao mesmo tempo, divergentes nesse item, pois enquanto uma das participantes afirma sentir-se desmotivada e sem vontade de exercer sua 
função, a outra se sente muito bem realizando tais atividades e compreendendo o seu papel como agente transformadora daquela comunidade. Podemos identificar essas variações nas seguintes falas:

Pouco eficiente. A falta de participação e resultados diminui a
motivação e, apesar de acreditar que a Educação. em Saúde
pode ser eficaz, há pouca vontade em realizar (Profissional A).

Acho muito bom e válido, pois posso ajudar as pessoas a refletir (sic) sobre sua própria realidade e tentar modifica-la por si mesmos (Profissional B).

É importante ressaltar que os sentimentos das participantes podem estar vinculados a outras questões - como as internas à própria pessoa - que não somente à desmotivação em relação ao trabalho. Sabe-se que questões internas podem interferir no desempenho das atividades profissionais e não se pode generalizar esses sentimentos, pois não sabemos as causas das motivações de qualquer profissional, até que sejam investigadas a fundo. Conforme Fernandes e Backs (2010), as experiências e sentimentos em relação às práticas educativas populares são expostas pelos profissionais como fator desmotivante.

Quanto à participação da equipe de profissionais da UBS nas atividades de Educação em Saúde, percebe-se, novamente, uma divergência nas respostas das participantes. Ao passo que uma delas afirma que a equipe não participa por ser desmotivada, a outra afirma que conforme os rodízios são estabelecidos, todos participam.

Não há um efetivo trabalho, porque a equipe é desmotivada e poucos se responsabilizam pela realização da Educação em Saúde (Profissional B).

Sim, porém, cada Educação em Saúde fica sob a responsabilidade de parte da equipe e há rodízio dos profissionais a cada Educação em Saúde. Todos participam a seu turno (Profissional A).

Pode-se perceber, aqui, diferentes olhares das profissionais em relação à equipe de trabalho. É preciso considerar que a própria desmotivação de uma delas em relação à atividade profissional pode ter levado à generalização de tal visão mais pessimista e desanimadora. Em contraste, a outra profissional pode ter um olhar mais otimista em relação ao trabalho realizado por ser, supostamente, uma pessoa que incentiva os colegas a trabalharem com a Educação em Saúde e, devido a essa atitude, veja mais e melhores resultados. 


\title{
Processo de Aprendizagem na Educação em Saúde: resultados alcança- dos
}

Essa categoria teve como objetivo avaliar as mudanças que ocorrem com os usuários ao passarem a utilizar o serviço de saúde e de como ocorre o processo de ensino e aprendizagem. Por meio das respostas das profissionais pesquisadas, percebemos que esse trabalho de Educação em Saúde sempre aponta uma mudança, por menor que seja, pois sempre ocorre algum aprendizado, percebido através da mudança de comportamento.

\begin{abstract}
Sim. Poucas mudanças ocorreram, mas alguns usuários relataram modificar a alimentação, usar os medicamentos corretamente e participar por um tempo de atividades físicas (Profissional B).
\end{abstract}

Algumas. Por exemplo, gestantes que passam a se cuidar melhor, param de fumar elou beber; idosos que passam a fazer atividade fisica, etc. (Profissional A).

Quem dá a palavra dá o tema, quem dá o tema dirige o pensamento, quem dirige o pensamento pode ter o poder de guiar a consciência. Esse é o método Paulo Freire (BRANDÃO, 2006). Ao refletirmos sobre as respostas com base no método Paulo Freire, percebemos que esse trabalho de Educação em Saúde é um processo que depende tanto do profissional quanto do paciente. De um lado, o profissional vai dar as informações e, de outro, cabe ao paciente refletir sobre o que lhe foi passado e colocar em ação dentro de suas possibilidades.

Como as mudanças são lentas e pequenas percebe-se a necessidade de ser um processo contínuo que necessita de constante aperfeiçoamento e necessidade de abordar o mesmo tema de diferentes maneiras e diversas vezes (Profissional B).

Através do diálogo com grupos populacionais sobre temas pertinentes, às vezes elaborados pela equipe e outras vezes solicitados pela população (Profissional A).

\section{Considerações finais}

Os autores entendem que este trabalho é de suma importância para a compreensão e, possivelmente, para a melhora dos processos de Educação em Saúde que ocorrem nas Unidades Básicas de Saúde (UBS). No município de Lages, em Santa Catarina, este provavelmente é o primeiro trabalho que procurou entender o processo de ensino e aprendizagem em uma UBS. 
Quando se fala de ensino e aprendizagem, é praticamente obrigatório trazermos as contribuições de Paulo Freire, pois para este autor a aprendizagem apenas ocorre quando o que é ensinado tem algum significado para a pessoa. Infelizmente, o que vemos em nosso país, de maneira geral, é que os conteúdos ensinados (seja em escolas, faculdades, cursos técnicos etc.) são um mero amontoado de informações, desconectados da realidade dos sujeitos. $\mathrm{Na}$ área da saúde isso não é diferente. Percebemos, por meio da literatura pesquisadas, que nas Unidades Básicas de Saúde do país predomina o ensino vertical, ou seja, aquele em os profissionais detêm o total saber, cabendo aos usuários apenas colocar em prática o que lhes é passado, sem possibilidade de qualquer tipo de troca.

As profissionais da UBS com quem realizamos esta pesquisa, no município de Lages, afirmaram que procuram realizar um processo de ensino e aprendizagem horizontal. Pelos dados coletados, percebe-se se que a equipe tem amplo conhecimento da realidade da população e que, nos dias em que ocorrem os encontros, procura-se estabelecer um diálogo com os sujeitos, na tentativa de adaptar as questões de saúde às necessidades da comunidade.

Ao mesmo tempo, foi possível constatar que a população ainda compreende que suas questões de saúde são de responsabilidade única dos profissionais da saúde, e age como se eles próprios não fossem responsáveis pela situação em que se encontram. Há também o imaginário de que o governo tem a obrigação de resolver os problemas de saúde apresentados pelos indivíduos. Segundo a enfermeira e a médica que contribuíram para esta pesquisa, é bastante árdua a tarefa de mudar essa ideia arraigada nos sujeitos. Essa questão veio ao encontro do que diz a literatura pesquisada, onde diversos autores afirmam o quanto é complicado convencer as pessoas de que elas também devem se responsabilizar pelos cuidados de sua própria saúde.

De outro lado, foi possível notar, por meio dos dados coletados no questionário e também em conversas informais, que, nesta área de estudo, muitos sujeitos ampliaram seus conhecimentos, inclusive colocando, nas reuniões, os problemas da comunidade e questionando os profissionais sobre os meios pelos quais é possível minimizar os danos causados pelas condições do meio socioeconômico em que estão inseridos. Exemplo disso é que a UBS pesquisada encontra-se em uma área bastante humilde, onde as ruas são de terra batida e o esgoto corre a céu aberto, inclusive em frente à própria Unidade.

Outra questão que surgiu foi a falta de apoio e coordenação da própria Secretaria de Saúde para a Educação em Saúde. Segundo relatos das profissionais, alguns moradores dificultam ou mesmo impedem que espaços comunitários (salão da igreja católica, por exemplo) sejam utilizados para as atividades propostas pelas equipes de saúde. As profissionais relataram que alguns moradores consideram-se donos de tais espaços, impedindo seu uso e impossibilitando a Educação em Saúde para a comunidade.

Com esta pesquisa, pretendemos iniciar um processo de compreensão e de uma possível contribuição para que a Educação em Saúde realmente ocorra de maneira efetiva e, principalmente, que seja um processo horizon- 
tal de troca entre a comunidade e os profissionais da saúde. Entendemos que são necessárias diversas outras pesquisas, inclusive nas demais Unidades Básicas de Saúde de Lages, para que se possa conhecer suas práticas, compará-las e, se possível, adaptá-las às várias realidades existentes dentro do município.

Por fim, é também urgente que haja uma gestão eficiente do processo de Educação em Saúde por parte da Secretaria Municipal de Saúde, contribuindo com as equipes na busca de soluções para as dificuldades relatadas. Esperamos que esta pesquisa incentive outros profissionais a estudarem o tema e a contribuírem, dentro de suas especialidades, para que esse processo seja efetivo e permita, verdadeiramente, a emancipação da população não apenas em relação à saúde, mas também em relação à sua realidade social, política, econômica e ambiental.

\section{Referências}

BRANDÃO, Carlos. R. O que é método Paulo Freire. São Paulo: Editora Brasiliense, 2006.

BRASIL (Ministério da Saúde). Saúde da Família: uma estratégia para a reorientação do modelo assistencial. Brasília: Ministério da Saúde, 1997

(Ministério da Saúde). Secretaria Executiva. Secretaria de Gestão do Trabalho e da Educação na Saúde. Glossário temático: gestão do trabalho e da educação na saúde. Brasília: Editora do Ministério da Saúde, 2008. 56 p. (Série A. Normas e Manuais Técnicos).

FERNANDES, Maria Clara Porto; BACKES, Vânia Marli Schubert. Educação em saúde: perspectivas de uma equipe da Estratégia Saúde da Família sob a óptica de Paulo Freire. Rev. bras. enferm., Brasília, DF, v.63, n.4, p.567-573, jul./ago. 2010. Disponível em: $<$ http://www.scielo. br/pdf/reben/v63n4/11.pdf $>$ Acesso em: 17 abr. 2013

MARCONI, Marina de Andrade. Técnicas de pesquisa: planejamento e execução de pesquisas, elaboração, análise e interpretação de dados. 4. ed. São Paulo: Atlas, 1999.

MINAYO, Maria Cecilia de Souza; DESLANDES, Suely Ferreira; OTAVIO CRUZ NETO, Romeu Gomes. Pesquisa social: teoria, método e criatividade. Petrópolis, RJ: Vozes, 1994.

PINAFO, Elisangela; NUNES, Elisabete, F. P. A.; GONZÁLEZ, Alberto Durán; GARANHANI, Mara Lúcia. Relações entre concepções e práticas de educação em saúde na visão de uma equipe de saúde da família. Trab. educ. saúde (Online), Rio de Janeiro, v. 9, n.2, p. 201-221, out. 2011. Disponível em: <http:/www.scielo.br/scielo.php?pid=S1981-77462011000200003\&script=sci_arttext> Acesso em: 23 abr. 2013

PINTO, Elizabeth Batista. A Pesquisa Qualitativa em Psicologia Clínica. Psicologia USP, São Paulo, v. 15 n. 1/2, p. 71-80, 2004. Disponível em: <http://www.scielo.br/pdf/pusp/v15n1-2/ a12v1512.pdf > Acesso em: 22 abr. 2013

RICHARDSON, Roberto Jarry et al. Pesquisa social: métodos e técnicas. São Paulo: Atlas, 1999. 
RODRIGUES, Carol Cardoso; RIBEIRO, Kátia Suely Queiroz Silva. Promoção da saúde: a concepção dos profissionais de uma unidade de saúde da família. Trab. educ. saúde, Rio de Janeiro, v.10, n.2, p.235-255, out. 2012. Disponível em: <http://www.scielo.br/scielo.php?pi-

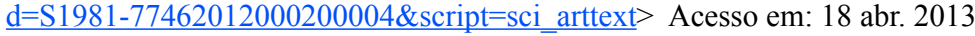

ROECKER, Simone; MARCON, Sonia Silva. Educação em saúde na estratégia saúde da família: o significado e a práxis dos enfermeiros. Esc. Anna Nery, Rio de Janeiro, v. 15, n. 4, p. 701-809, dez. 2011. Disponível em: <http://www.scielo.br/scielo.php?pi-

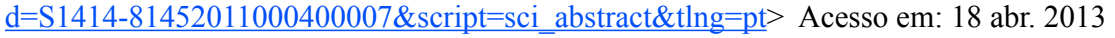

SILVA, Cristiane Maria da Costa; MENEGHIM, Marcelo de Castro; PEREIRA, Antônio Carlos; MIALHE, Fábio Luiz. Educação em saúde: uma reflexão histórica de suas práticas. Ciênc. saúde coletiva, Rio de Janeiro, v. 15, n. 5, p.2539-2550, ago. 2010. Disponível em: $<\underline{\mathrm{http}: / /}$ www.scielo.br/scielo.php?pid $=$ S1413-81232010000500028\&script $=$ sci arttext $>$ Acesso em: 25 abr. 2013

Submissão em: 11/06/2013

Revisão em: 02/07/2013

Aceite em: 26/07/2013

Anderson Chagas de Oliveira é Bacharel em Geografia pela UFRJ (2004), mestre em Saúde Pública, pela ENSP/Fiocruz (2006) e graduando em Psicologia na Universidade do Planalto Catarinense - UNIPLAC (2011-2015). Endereço para correspondência: Rua Augusto Ribeiro Rosa, 347. Frei Rogério. CEP 88508-240. Lages/ SC, Brasil. E-mail: andersonchagasoliveira1981@gmail.com

Bruna Pereira Dondé é graduanda em Psicologia da Universidade do Planalto Catarinense - UNIPLAC (2011-2015). E-mail: bruna_donde21@hotmail.com

Ana Paula Veloso é graduanda em Psicologia da Universidade do Planalto Catarinense -UNIPLAC (2011-2015). E-mail: paulinhah_v@hotmail.com

Priscila Godinho da Silva é graduanda em Psicologia da Universidade do Planalto Catarinense-UNIPLAC (2011-2015).

E-mail: priscilinhags@hotmail.com

Rodrigo Diaz de Vivar Y Soler é Professor do Centro Universitário Estácio de Sá/SC e da Universidade do Planalto Catarinense (UNIPLAC). Bacharel em Psicologia pela UNESC, mestre em Psicologia e doutorando em Psicologia pela Universidade Federal de Santa Catarina.

E-mail: diazsoler@gmail.com 